\title{
Relating Xylem Cavitation to Gas Exchange in Cotton
}

\author{
Dennis C. Gitz III*, Jeffrey T. Baker, Robert J. Lascano \\ Cropping Systems Research Laboratory, USDA-ARS", Lubbock, USA \\ Email: ${ }^{*}$ dennis.gitz@ars.usda.gov
}

Received 27 March 2015; accepted 20 July 2015; published 23 July 2015

Copyright (C) 2015 by authors and Scientific Research Publishing Inc.

This work is licensed under the Creative Commons Attribution International License (CC BY). http://creativecommons.org/licenses/by/4.0/

(c) (†) Open Access

\begin{abstract}
Acoustic emissions (AEs) from xylem cavitation events are characteristic of transpiration processes. Though a body of work exists describing AEs and limited stem hydraulic conductivity under water stress, there is limited information about the effects of AEs on stomatal aperture and limitation on carbon assimilation. The objective of this work was to relate AEs to drought stress in cotton. Cotton was grown in mini-lysimeters in the greenhouse and instrumented with a portable photosynthesis system and ultrasonic transducers connected to a digital signal-processing unit. Whole plant transpiration, leaf level gas exchange and ultrasonic AEs were measured. Xylem cavitation events temporally associated with the onset of drought stress. The results are consistent with stomatal closure in response to reduced hydraulic conductance from xylem cavitation events. Clear direct empirical evidence of a reduction in carbon assimilation associated with xylem cavitation resulting from water stress is presented.
\end{abstract}

\section{Keywords}

Xylem Cavitation, Drought Stress, Stomatal Control, Irrigation Scheduling

\section{Introduction}

Crop water availability is a primary determinant of growth and yield [1] [2], but also see [3]. Water suitable for

\footnotetext{
${ }^{*}$ Corresponding author.

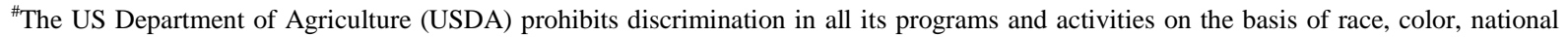
origin, age disability, and where applicable, sex, marital status, familial status, parental status, religion, sexual orientation, genetic information, political beliefs, reprisal, or because all or part of an individual's income is derived from any public assistance program (Not all prohibited bases apply to all programs.) Persons with disabilities who required alternative means for communication of program information (Braille, large print, audiotape, etc.) should contact USDA's TARGET Center at (202) 720-2600 (voice and TDD). To file a complaint of discrimination, write to USDA, Office of Civil Rights, 1400 Independence Avenue, S.W., Washington DC 20250-9410, or call (800) 7953272 (voice) or (202) 720-6382 (TDD). USDA is an equal opportunity provider and employer.
} 
irrigation continues to become more restricted because of increased competition between users, diminished availability, and social policy [2]. In arid or semi-arid regions where thermal limitation and season length do not greatly limit cotton cropping [4] water availability is the predominant yield-determining factor. In semiarid agricultural regions crop irrigation can represent $>95 \%$ of the total freshwater use, such as in the case of the Southern High Plains (SHP) in the United States [5]. Aquifer recharge rates in such areas are often very low in comparison to withdrawl so that groundwater is considered an essentially non-renewable resource; for example, pumping groundwater from the Ogallala Aquifer in the SHP is equivalent to "mining" ancient ground water [6]. Because of increasing constraints on irrigation water worldwide, considerable effort has been expended on the development of more efficient irrigation strategies for crop production systems.

Irrigation scheduling of crop plants, especially indeterminate plants such as cotton, is difficult because growth and development is responsive to environmental conditions throughout the growing season. Cotton is especially problematic for such reasons. While cotton crop models exist which could, in principle, be used to assess the potential effect of an irrigation event on end of season lint yield such models have found limited use in irrigation scheduling [7] [8]. The limited use of plant models in irrigation scheduling might be due to the complexity surrounding the initial parameterization of such models, the lack of intuitive user interfaces that would provide producers well organized and easily understood information, and because it is difficult for most growers to understand the underlying principles, potential benefits and limitations of such systems.

The most widely used cotton irrigation scheduling approaches are based on evaporative demand calculations or soil water measurements [9] [10]. However, a few methods do exist which measure biologic parameters as a basis for irrigation scheduling rather than the proximate soil and environmental parameters that are either causally related or empirically correlated to crop performance [10] [12]. For example, cotton canopy temperature has repeatedly been suggested as a measurable surrogate for plant stress and as a basis for scheduling irrigation events [13]-[18].

Irrigation scheduling approaches based solely upon cotton canopy temperature are easily understood and simple to use but suffer from potential pitfalls. Canopy temperature based irrigation strategies such as the Time Temperature Threshold [16] [19] or the Biologically-Identified Optimal Thermal Interactive Console systems [20] that were developed and tested in semi-arid environments suffer from the drawback that ambient air temperature, humidity, and solar radiation also influence canopy temperature. High humidity has been both theoretically and empirically shown to be a confounding factor; when humidity is high, such systems tend to overestimate crop stress [19]-[22]. This limits attempts to extend such schemes to humid field environments or greenhouse production settings. Efforts to control irrigation based on canopy temperature eventually require additional parameterization or environmental inputs. Evaluating additional biologic or physical factors can improve the accuracy of stress assessment but increases complexity [17]-[23]. Ideally, the incorporation of a robust, easily measured, simply assessed biological drought signal into existing irrigation control technologies would increase the efficacy of existing irrigation scheduling systems, or perhaps even lead to the development of new irrigation control strategies.

In the mid-1960s Milburn, Johnson, Tyree and others described the detection of Acoustic Emissions (AEs) from xylem cavitation events. These observations provided additional support for the cohesion-tension theory of sap ascent in plants [24]. Since then, paradoxical observations such as rapid embolism repair, unexpected xylem pressures, and potential artifacts of xylem pressure measuring have been interpreted to disprove the cohesion-tension theory, or at the very least to illustrate that xylem transport processes are poorly understood [25]-[28]. Nevertheless, the fundamental underpinnings of the cohesion-tension theory are generally accepted since it is "the only theory consistent with the preponderance of data on water transport in plants" [29].

Maintenance of transpiration rates requires that forces imposed upon xylem water columns by evapo-transpirative losses from aerial surfaces overcome both hydraulic resistance within the xylem and soil-root water transport limitations. The resulting tension imposed upon the water column within the xylem leads to cavitation when the water column's tensile strength is exceeded or through processes related to gas bubble seeding, hydrophobic vessel features, or gas dissolution processes [26]. Regardless of the mechanism, cavitation results from a strain related failure of a physical structure (the water column) from applied stresses (surface tension at evaporating surfaces, hydraulic conductance, and soil moisture availability). Stem hydraulic limitations imposed by xylem embolisms results in lowered stomatal conductance [30]. Lowered xylem hydraulic conductance tends to limit productivity, perhaps through stomatal responses resulting in diffusive limitation to $\mathrm{CO}_{2}$ assimilation, though this has never been clearly empirically demonstrated [31]-[33]. If a clear causal relationship between 
AEs and photosynthesis reduction could be drawn, then AE detection might yield the capacity to directly sense the physiological mechanisms responsible for drought stress limitation to crop performance.

While AE sensing has contributed greatly to the understanding of xylem hydraulics, very few investigations have attempted to use AE sensing to schedule irrigation [10] [34]-[36]. No attempts at AE based irrigation scheduling have been reported with major agronomic field cropping systems such as cotton, although AE has been used as a physiological research tool using corn and other species as model plants [37] [38].

The primary objective of this work was to investigate the relationship of AEs from xylem cavitation events to gas exchange in and to obtain preliminary observations to determine whether AE emissions from cavitation events might be used as a plant water stress signal in cotton. Cotton was selected as a model plant because it is a woody plant which lends itself to such work, because of its importance to semiarid agriculture, and because of the considerable interest in understanding and sensing water stress in this crop plant. The working hypothesis was that stomatal closure is associated with, and perhaps causally related to xylem cavitation events. Hence, we expected that AEs would be related to decreased performance as a reduction in net carbon assimilation $\left(A_{\text {net }}\right)$ in cotton [17] [31]-[33].

\section{Materials and Methods}

\subsection{Overview}

The techniques used were based and expanded upon those described by other workers [35] [36] [39]. The experiments were conducted in a polyhouse at the ARS-USDA facility in Lubbock TX. Briefly, we measured leaf and whole plant gas exchange and attempted to relate these to xylem cavitation events. The experimental setup is shown in Figure 1 in which most of the leaves of one of the plants used in the work were removed for clarity.

\subsection{Plant Culture}

Upland cotton plants (Gossypium hirsutum L. var. hirsutum cvar. Fibermax 951) were grown in insulated containers that functioned as 'soil bins' in a minilysimeter system [40]. The soil bins were constructed of white high density 12 liter polyethylene buckets that had been drilled and tapped to accept two barbed nylon hose fittings and stopcock valves to allow for and control drainage. The openings of the fittings facing the bucket interior were covered with common fiberglass window screen to prevent clogging and ensure even drainage. The buck-

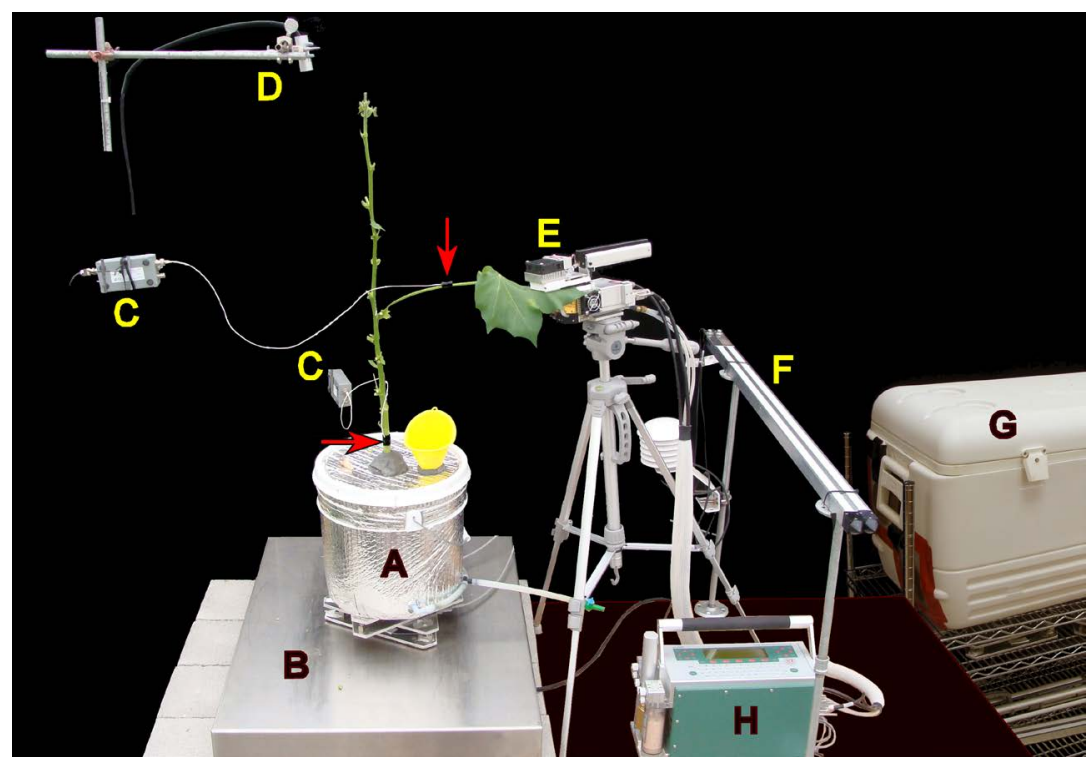

Figure 1. Diagram of the experimental apparatus. Figure is made from an image captured after termination of an experiment. Except for the leaf in the cuvette of the photosynthesis analyzer, all leaves have been removed from the plant for clarity. (A) Insulated container with plant; (B) Scales; (C) Pre-amplifiers; (D) Infrared thermometer; (E) Gas exchange cuvette clamped on leaf; (F) Linear PAR sensors; (G) Digital signal processing unit/computer interface and data-logger within insulated housing; (H) LI-6400 photosynthesis measuring system. Red arrows indicate ultrasonic transducers. 
ets and lids were covered with reflective aluminized polyethylene bubble insulation (Reflectix ${ }^{\circledR}$ Double Reflective Insulation ${ }^{1}$; Reflectix Inc., Markleville, IN) that was bonded to the lids and sides of the buckets with aerosol contact cement (3M $\mathrm{M}^{\mathrm{TM}}$ Super $77^{\mathrm{TM}}$ Multipurpose Adhesive, St. Paul, $\mathrm{MN}$ ) to prevent solar loading and localized heating of the plant roots during development and experimentation. The bucket lids were provided with butadiene rubber gaskets so the joint between the lid and the bucket was gas tight. A $5 \mathrm{~cm}$ diameter circular opening was cut into the center of each lid to accommodate the shoot and allow the plant to grow from the covered bucket. A smaller hole was provided towards the edge of the lid into which a drip emitter or funnel could be inserted for irrigation during development and experimentation, respectively. About $0.5 \mathrm{~L}$ of horticultural Perlite was used to cover the screened outlets, the buckets filled with a commercial peat based potting mix (Sunshine Traditional Loose Fill mix; Sungro Horticultural Products, Bellvue, WA; www.sungro.com), the lids sealed onto the buckets, the medium saturated to field capacity by irrigating to runoff several times over about an hour, and three seeds were pushed about $2.5 \mathrm{~cm}$ into the growth medium into the center of each bucket.

After the cotyledons were fully expanded the stand was thinned to a single plant per bucket. The plants were fertigated daily with an automated horticultural drip delivery system to well past the drip point with a complete nutrient solution. The nutrient solution consisted of $11 \mathrm{~kg}$ of Peter's ExCel Multipurpose fertilizer (Scotts Company LLC, Marysville OH) brought to $189 \mathrm{~L}$ and subsequently injected into the irrigation water at a ratio of 1:150 (v:v, fertilizer solution:municipal water). The plants were allowed to develop for eight weeks, after which the plants had about 15 nodes and the first blooms were visible. A soil bin containing a fairly symmetric plant with minimal mechanical and/or insect damage was selected for subsequent experimentation. Just before dawn each day a one hour square-wave pulse of $80 \mu \mathrm{mol} \cdot \mathrm{m}^{-2} \cdot \mathrm{s}^{-1}$ was delivered by mercury vapor lamps to extend the photoperiod of other plants in the polyhouse.

\subsection{Gas Exchange Measurements}

After selecting a plant, the gap between the plant shoot and the lid was sealed with a non-toxic duct putty (Gardener Bender \# DS-110, Milwaukee WI). A plastic funnel was inserted into the second hole, and the gap between the funnel and the lid was sealed likewise. The whole arrangement was then centered upon a scale (Ohaus Model IS300IGG-H1, Sartorius Corp., Edgewood, NY) that had been placed upon a massive bench constructed from stacked concrete blocks and topped with a heavy wooden platform to minimize vibration. Water was added to the lysimeter through the funnel until the rooting medium was at field capacity as evidenced by runoff. After allowing the lysimter to drain, the stopcock was closed, the mass of the system noted, and the experiment was initiated by adding water through the funnel until the mass of the system was $1.0 \mathrm{~kg}$ more than the mass at field saturation (runoff point). A ping-pong ball was dropped into the funnel to seal the system. Output from the resulting mini-lysimeter was collected as an ASCII string from the scale and recorded with a programmable datalogger (Model CR-3000, Campbell Scientific Corporation, Logan, UT). Upon termination of the experiment, whole plant transpiration was calculated from the digital scale output $\left(\mathrm{g} \cdot \mathrm{s}^{-1}\right)$, converted to a mole basis, and adjusted for the whole plant leaf area $\left(\mathrm{mmol} \cdot \mathrm{m}^{-2} \cdot \mathrm{s}^{-1}\right)$ which was determined by passing each leaf through a LI-3100C leaf area meter (Li-Cor).

A fully expanded leaf unshaded by fruiting branches arising from the main stem about midway up the plant (node \# 7) was selected for monitoring leaf level gas exchange at $30 \mathrm{~s}$ intervals using a portable photosynthesis system (Model LI-6400xt, Li-Cor Biosciences, Lincoln, NE) with a $2 \times 3 \mathrm{~cm}$ leaf cuvette and 6400-02B LED light source delivering photosynthetically active radiation (PAR) levels measured with a line quantum sensor. Line sensors were used in this work rather than point sensors to minimize potential errors resulting from shading by the polyhouse structure, and to better estimate the radiation regime experienced by the whole plant. The system was set to maintain a constant $28^{\circ}$ block temperature. The $\mathrm{CO}_{2}$ and $\mathrm{H}_{2} \mathrm{O}$ vapor within the cuvette were not controlled. Rather, air was drawn at a constant $500 \mu \mathrm{mol} \cdot \mathrm{min}^{-1}$ rate from outside the polyhouse and passed through a $20 \mathrm{~L}$ buffer volume to eliminate abrupt changes in $\mathrm{CO}_{2}$ and water vapor concentration.

Environmental conditions within the polyhouse were measured with commercially available transducers positioned about a meter from the plant and recorded with a programmable datalogger at $5 \mathrm{~s}$ intervals (Model CR-3000, Campbell Scientific Corporation, Logan UT). Air temperature and humidity were measured with a platinum resistance thermometer and humidity sensor (Model HMP-50, Campbell Sci.) housed within a six plate naturally-aspirated radiation shield. Photosynthetically active radiation (PAR) was measured with a one meter

${ }^{1}$ Mention of trade names or commercial products in this publication is solely for the purpose of providing specific information and does not imply recommendation or endorsement by the US Department of Agriculture. 
linear light sensor (LI-191 Line Quantum Sensor, Li-Cor). An infrared thermometer (Model SI-121 Infrared Radiometer, Apogee Instruments Inc., Logan UT) was placed above and slightly to the North of the apex of the plant to measure 'canopy' temperature.

Clear skies were experienced throughout most of the experiment, with the exception of the last full day, during which some high broken cloud cover was experienced. Nevertheless, the diurnal radiation regime was similar from the start of the experiment on DOY 289 through the imposition of drought stress on DOY 292. A consistent deviation from the sinusoidal diurnal solar radiation distribution resulted from shading by elements of the polyhouse structure and from the different light transmission characteristics of the roof and wall materials.

\subsection{Acoustic Emissions (AEs)}

Acoustic emissions arising from xylem cavitation events were detected with low mass miniature epoxy faced piezoelectric transducers having an operating frequency range of $100-1000 \mathrm{kHz}$ (Model S9220, Physical Acoustics Corp., MISTRAS Group, Inc., Princeton Junction, NJ) acoustically coupled to the plant with a small amount of high vacuum silicone stopcock grease placed on the face of the transducer. The transducers were fixed to the upper surface of the petiole or the base of the main stem with black PVC electrical tape. Transducer output was conditioned with a $20-1200 \mathrm{kHz}$ active bandpass pre-amplifier set to $60 \mathrm{db}$ gain (Model 2/4/6, Physical Acoustics) and analyzed with a microDiSP ${ }^{\mathrm{TM}}$ acoustic digital signal processing and detection system (Physical Acoustics Corp.) driven by a notebook computer running AE Win for DiSPTM (Physical Acoustics Corp.) software configured to detect and log signals $>35 \mathrm{~dB}$ (4.75 $\mu \mathrm{V}$ threshold) within a $100-200 \mathrm{kHz}$ range. The instrumentation was housed in a large marine grade insulated cooler actively aspirated with muffin fans to minimize heat buildup from solar radiation and electronic equipment.

\section{Results}

For presentation, all the results have been combined into a single graphic (Figure 2) to allow the reader to more easily visualize the inter-related physiological processes during the onset of drought stress. Graphs are stacked vertically so that time as Day of Year (DOY) can be traced upwards through the presentation from the DOY axis. No more than two plots were used within each frame. Rather than clutter graphics with legends, the colors of the plots correspond to the axis labels and axes. Images were collected during the experiment with a digital camera to provide a crude indication of plant water status as visible loss of turgor (wilting). These are displayed across the top of the graphic and the times the images were acquired are indicated both by letters A through $\mathrm{E}$ and with arrows that indicate the times along the abscissa. Plants appeared turgid from the beginning of the experiments through the early morning of DOY 292 after which some wilting was observed (indicated as time-point "C" in Figure 1). Wilting then became more severe throughout DOY 292 (D \& E) and was evident throughout the remainder of the experiment $(\mathrm{F})$.

Whole plant and leaf level transpiration exhibited remarkably similar diurnal patterns. Leaf to leaf intra-canopy shading reduced solar loading to some leaves and reduced calculated maximal whole plant transpiration rates to about $75 \%$ of leaf level. In the mid-morning of DOY 292 drought stress resulted in reduced transpiration at both the leaf and whole plant levels. Similar to transpiration, net assimilation $\left(A_{\text {net }}\right)$ tracked radiation levels until the onset of drought stress, which was characterized by the response of several physiological parameters. The onset of drought stress was observed as; 1) reduced transpiration and a separation of the transpiration and assimilation curves, 2 ) rising leaf and canopy temperature depression $\left(\mathrm{T}_{\text {leaf }}-\mathrm{T}_{\text {air }}\right.$ and $\left.\mathrm{T}_{\text {canopy }}-\mathrm{T}_{\text {air }}\right)$, respectively), 3) a "breaking over" and subsequent pronounced diurnal hysteresis in the $\mathrm{A}_{\text {net }}$ to photosyntehtically active radiation (PAR) plots and, 4) an increased rate of cavitation events in both the petiole and main stem.

Transpiration was more sensitive to drought stress than $\mathrm{A}_{\text {net }}$, consistent with the depressed substomatal $\mathrm{CO}_{2}$ concentration within the leaves (not presented). The effect of drought stress on $A_{\text {net }}$ is perhaps most apparent in diurnal plots of $A_{n e t}$ as a function of PAR. On DOY 292 these plots reveal pronounced hysteresis (Time points C through E) resulting from sharply decreased Anet at time point C. In addition however, a clear albeit subtle change in the response of $A_{\text {net }}$ was detected as PAR passed $250 \mu \mathrm{mol} \cdot \mathrm{m}^{-2} \cdot \mathrm{s}^{-1}$ in the early morning, visible as a 'breaking over' in the plot temporally coinciding with sharply increasing temperature depression $\left(\mathrm{T}_{\text {leaf }}-\mathrm{T}_{\text {air }}\right.$ and $\mathrm{T}_{\text {canopy }}-\mathrm{T}_{\text {air }}$ ).

Cumulative AEs and AE rates generally increased in both the main stem and petiole as the plant depleted the available water (and mass of the system decreased). Increased petiole AE rate was associated with reduced leaf 

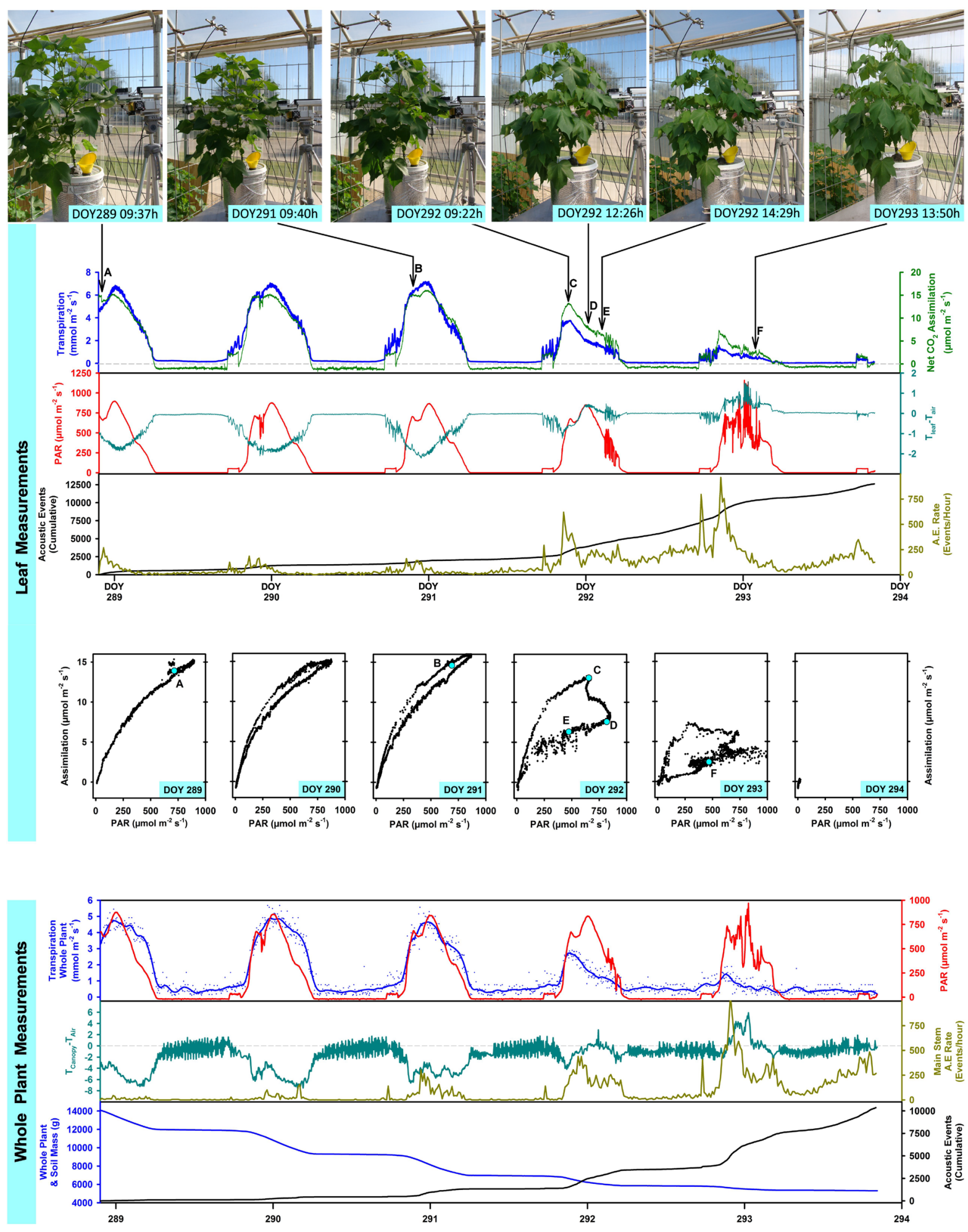

Figure 2. Response of selected physiological parameters in a cotton plant to drought stress gradually imposed over several days. Top: Images along top of figure show appearance of plant at selected time points "A" through " $F$ ". Middle: Central group of plots labeled "Leaf Measurements" are selected gas exchange parameters and acoustic emissions data for a single leaf and petiole, respectively. Time points "A" thru "F" are indicated within plots. Bottom: Plots labeled "Whole Plant Measurements" are whole plant transpiration and acoustic emissions data. Each plot is identified by matching line plot color to that of the corresponding axis. 
transpiration, $A_{n e t}$ and reduced leaf temperature depression. A similar though less pronounced relationship was seen with main stem AEs, whole plant transpiration, and canopy temperature depression. Main stem AEs more gradually increased with water use as compared to the petiole.

Whole plant, or main stem $\mathrm{AE}$ data were also sensitive to stomatal opening induced by predawn supplemental lighting. Each morning, pre-dawn supplemental lighting elicited a remarkable spike in both petiole and main stem AEs that was clearly associated with increased transpiration. During the predawn supplemental illumination leaf transpiration, leaf temperature depression and $\mathrm{AE}$ rate exhibited oscillations with a frequency of about 15 min'cycle ${ }^{-1}$.

\section{Discussion}

Plant stress responses are often characterized by damage leading to reductions in various aspects of metabolism, or in growth and development, resulting from an applied or increased level of a stressor as compared to a plant's "normal" growing conditions [41]. An exception to this view is the case of crop plants. The definitions of crop stress effects are often extended to include reduced crop yields from a theoretical maximum; whether the result of actual stress damage or of sub-optimal environmental conditions. A primary objective of the producer is to maximize the return (yield response) for a given crop input (applied irrigation water). For these reasons, plant based agricultural irrigation scheduling strategies are an exercise in the detection and management of crop plant stress.

As water becomes limited, stomatal aperture decreases and begins to limit transpiration. Correlation of drought stress to stomatal limitation of leaf water vaporization is an underlying principle in canopy temperature based irrigation scheduling methods. Such methods use canopy temperature as a surrogate for stress or as one of a set of parameters with which plant stress is calculated. Plant stress in and of itself, as a deviation from optimal physiological performance, cannot be directly measured, at least not easily or inexpensively. For this reason plant based irrigation scheduling methods often rely on the measurement of surrogates for plant stress. There are predominantly two broad approaches to measuring plant stress (surrogates). These involve 1) direct or indirect measurement of transpiration loss or 2) determination of the water content or hydraulic status of the plant tissues [10] [11]. In this work we defined crop performance as $A_{\text {net }}$ and stress as a reduction in $A_{\text {net }}$ over several environmentally similar days while water availability gradually diminished (17). We attempted to temporally link direct measures (whole plant and leaf level transpiration) and indirect measures (leaf and canopy temperature depression) of water use to AEs as an indicator of the hydraulic status of the stems. Because all of the physiological stress responses observed in the present work were temporally linked, our results are consistent with, and provide direct empirical evidence of the idea that reduced soil water availability leads to xylem embolisms resulting in hydraulic limitations, lowered stomatal conductance, and subsequent diffusive stomatal limitation of $\mathrm{A}_{\text {net }}(30$ - 33).

Stomata are the primary pathways for the exchange of both carbon dioxide and water vapor between the interior leaf photosynthetic tissues and the atmosphere. It has long been suggested that stomatal aperture functions to optimize or at least to balance water loss and carbon assimilation [42]. An alternate view is that plants, especially crop plants, tend to maximize, rather than optimize, performance and "operate at the edge of dysfunction" [43]. In this view, an adaptive advantage conferred by stomata in angiosperms is to prevent catastrophic xylem embolism rather than respond to reduced hydraulic conductivities resulting from xylem cavitation [42] [44]-[46]. It should be borne in mind that while the present work is consistent with both the ideas of a feedback and feed-forward mechanism of stomatal control, the temporal resolution of the experiments did not allow disproof of either. Nevertheless, the large spike in whole plant and petiole AEs elicited by low predawn radiation preceded subsequent stomatal cycling. We suggest that future experimentation with higher temporal resolution, perhaps on the order of one second, will be able to separate and group the observed phenomena into causes and responses.

There is considerable interest in xylem cavitation from both applied and pure scientific perspectives. Xylem cavitation and stomatal aperture are related but exactly how remains unclear, or at least the mechanisms are apparently not generally accepted. While evidence presented here is consistent with a causal relationship, whether stomata respond to hydraulic conditions arising from xylem cavitation events (feedback), or whether stoma respond to conditions that may lead to xylem cavitation (feed-forward) remains a subject of investigation [30] [46]-[48]. 


\section{Conclusions}

Xylem cavitation is a strain related failure of physical structure within a plant. While not conclusive, the results presented herein are consistent with the view that cavitation, the failure of water columns within xylem, results in diminished physiological performance through subsequent processes such as stomatal closure. Hence, the significance is that detection of AEs from xylem cavitation represents one of the few, if not the only direct measures of a well defined plant stress events that subsequently lead to reduced crop performance.

Drought stress as reduced net carbon assimilation is clearly associated with xylem cavitation in cotton. These results are consistent with a causal relationship; that xylem cavitation results in reduced stem hydraulic conductance, reduced stomatal conductance, and diminished physiological performance. This study is also significant in that it is, to our knowledge, the first clear empirical demonstration that xylem cavitation could be directly associated with stomatal responses resulting in diffusive limitation to $\mathrm{CO}_{2}$ assimilation.

\section{Acknowledgements}

This research was supported, in part, by the Ogallala Aquifer Program, a consortium between USDA-Agricultural Research Service, Kansas State University, Texas AgriLife Research, Texas AgriLife Extension Service, Texas Tech University, and West Texas A \& M University.

\section{References}

[1] Boyer, B.S. (1986) Advances in Drought Tolerance in Plants. Advances in Agronomy, 56, 187-218. http://dx.doi.org/10.1016/S0065-2113(08)60182-0

[2] Morison, J.I.L., Baker, N.R., Mullineaux, P.M. and Davies, W.J. (2008) Improving Water Use in Crop Production. Philosophical Transactions of the Royal Society, B: Biological Sciences, 363, 639-658. http://dx.doi.org/10.1098/rstb.2007.2175

[3] Turner, N.C. (1990) Plant Water Relations and Irrigation Management. Agricultural Water Management, 17, 59-73. http://dx.doi.org/10.1016/0378-3774(90)90056-5

[4] Howell, T.A., Evett, S.R., Tolk, J.A. and Schneider, A.D. (2004) Evapotranspiration of Full-Deficit-Irrigated, and Dryland Cotton on the Northern Texas High Plains. Journal of Irrigation and Drainage Engineering, 130, 277-285. http://dx.doi.org/10.1061/(ASCE)0733-9437(2004)130:4(277)

[5] TWDB (2012) Water for Texas 2012: The 2012 State Water Plan. Chapter 2, Regional Summaries: Summary of Llano Estacado (O) Region, Texas Water Development Board, Austin, 116-121. http://www.twdb.texas.gov/publications/state water plan/2012/02.pdf

[6] Brooks, E., Emel, J., Jokisch, B. and Robbins, P. (2000) The Llano Estacado of the US Southern High Plains: Environmental Transformation and the Prospect for Sustainability. United Nations University Press, New York, 111-156.

[7] Whisler, F.D., Acock, B., Baker, D.N., Fye, R.E., Hodges, H.F., Lambert, J.R., Lemmon, H.E., McKinion, J.M. and Reddy, V.R. (1986) Crop Simulation Models in Agronomic Systems. In: Brady, N.C., Ed., Advances in Agronomy, Academic Press, 141-208. http://dx.doi.org/10.1016/S0065-2113(08)60282-5

[8] Evett, S.R. and Tolk, J.A. (2009) Introduction: Can Water Use Efficiency Be Modeled Well Enough to Impact Crop Management? Agronomy Journal, 101, 423-425. http://dx.doi.org/10.2134/agronj2009.0038xs

[9] Allen, R.G., Pereira, L.S., Raes, D. and Smith, M. (1998) Crop Evapotranspiration. Guidelines for Computing Crop Water Requirements. FAO, Rome, FAO Irrigation and Drainage Paper No. 56,300 p. http://www.kimberly.uidaho.edu/water/fao56/fao56.pdf

[10] Jones, H.G. (2007) Monitoring Plant and Soil Water Status: Established and Novel Methods Revisited and Their Relevance to Studies of Drought Tolerance. Journal of Experimental Botany, 58, 119-130. http://dx.doi.org/10.1093/jxb/erl118

[11] Jones, H.G. (2004) Irrigation Scheduling: Advantages and Pitfalls of Plant-Based Methods. Journal of Experimental Botany, 55, 2427-2436. http://dx.doi.org/10.1093/jxb/erh213

[12] Greenwood, D.J., Zhang, K., Hilton, H.W. and Thompson, A.J. (2010) Opportunities for Improving Irrigation Efficiency with Quantitative Models, Soil Water Sensors and Wireless Technology. Journal of Agriculture Science, 148, 116. http://dx.doi.org/10.1017/S0021859609990487

[13] Mahan, J.R. and Upchurch, D.R. (1988) Maintenance of Constant Leaf Temperature by Plants: I. Hypothesis-Limited Homeothermy. Environmental and Experimental Botany, 28, 351-357.

http://dx.doi.org/10.1016/0098-8472(88)90059-7 
[14] Upchurch, D.R. and Mahan, J.R. (1988) Maintenance of Constant Leaf Temperature by Plants—II. Experimental Observations in Cotton. Environmental and Experimental Botany, 28, 359-366. http://dx.doi.org/10.1016/0098-8472(88)90060-3

[15] Wanjura, D.F., Upchurch, D.R. and Mahan, J.R. (1992) Automated Irrigation Based on Threshold Canopy Temperature. Transactions of the American Society of Agricultural Engineers, 35, 1411-1417. http://dx.doi.org/10.13031/2013.28748

[16] Wanjura, D.F., Upchurch, D.R. and Mahan, J.R. (1995) Control of Irrigation Scheduling Using Temperature-Time Thresholds. Transactions of the American Society of Agricultural Engineers, 38, 403-409. http://dx.doi.org/10.13031/2013.27846

[17] Baker, J.T., Gitz III, D.C., Payton, P., Wanjura, D.F. and Upchurch, D.R. (2007) Using Leaf Gas Exchange to Quantify Drought in Cotton Irrigated Based on Canopy Temperature Measurements. Agronomy Journal, 99, 637-644. http://dx.doi.org/10.2134/agronj2006.0062

[18] Gunderson, C.A., O’Hara, K.H., Campion, C.M., Walker, A.V. and Edwards, N.T. (2010) Thermal Plasticity of Photosynthesis: The Role of Acclimation in Forest Responses to a Warming Climate. Global Change Biology, 16, 2272 2286. http://dx.doi.org/10.1111/j.1365-2486.2009.02090.x

[19] Wanjura, D.F. and Upchurch, D.R. (1995) Calculating Time Thresholds for Irrigation Scheduling. Proceedings of the Beltwide Cotton Conferences, San Antonio, 4-7 January 1995, 449-452.

[20] Mahan, J.R., Burke, J.J., Wanjura, D.F. and Upchurch, D.R. (2005) Determination of Temperature and Time Thresholds for BIOTIC Irrigation of Peanut on the Southern High Plains of Texas. Irrigation Science, 23, 145-152. http://dx.doi.org/10.1007/s00271-005-0102-9

[21] Wanjura, D.F. and Upchurch, D.R. (1997) Accounting for Humidity in Canopy-Temperature-Controlled Irrigation Scheduling. Agricultural Water Management, 34, 217-231. http://dx.doi.org/10.1016/S0378-3774(97)00024-3

[22] Blonquist Jr., J.M., Norman, J.M. and Bugbee, B. (2009) Automated Measurement of Canopy Stomatal Conductance Based on Infrared Temperature. Agricultural and Forest Meteorology, 149, 2183-2197. http://dx.doi.org/10.1016/j.agrformet.2009.10.003

[23] Widmoser, P. (2010) An Alternative to Define Canopy Surface Temperature Bounds. Agricultural Water Management, 97, 224-230. http://dx.doi.org/10.1016/j.agwat.2009.09.012

[24] Tyree, M.T. and Sperry, J.S. (1989) Vulnerability of Xylem to Cavitation and Embolism. Annual Review of Plant Physiology and Molecular Biology, 40, 19-36. http://dx.doi.org/10.1146/annurev.pp.40.060189.000315

[25] Canny, M.J. (1995) A New Theory for the Ascent of Sap-Cohesion Supported by Tissue Pressure. Annals of Botany, 75, 343-357. http://dx.doi.org/10.1006/anbo.1995.1032

[26] Tyree, M.T. (1997) The Cohesion-Tension Theory of Sap Ascent: Current Controversies. Journal of Experimental Botany, 48, 1753-1765. http://dx.doi.org/10.1093/jxb/48.10.1753

[27] Meinzer, F.C., Clearwater, M.J. and Goldstein, G. (2001) Water Transport in Trees: Current Perspectives, New Insights and Some Controversies. Environmental and Experimental Botany, 45, 239-242. http://dx.doi.org/10.1016/S0098-8472(01)00074-0

[28] Zimmermann, U., Schneider, H., Wegner, L.H. and Haase, A. (2004) Water Ascent in Tall Trees: Does Evolution of Land Plants Rely on a Highly Metastable State? New Phytolologist, 162, 575-615. http://dx.doi.org/10.1111/j.1469-8137.2004.01083.x

[29] Angeles, G., Bond, B., Boyer, J.S., Brodribb, T., Brooks, J.R., Burns, M.J., Cavender-Bares, J., Clearwater, M., Cochard, H., Comstock, J., Davis, S.D., Domec, J.-C., Donovan, L., Ewers, F., Gartner, B., Hacke, U., Hinckley, T., Holbrook, N.M., Jones, H.G., Kavanagh, K., Law, B., López-Portillo, J., Lovisolo, C., Martin, T., Martínez-Vilalta, J., Mayr, S., Meinzer, F.C., Melcher, P., Mencuccini, M., Mulkey, S., Nardini, A., Neufeld, H.S., Passioura, J., Pockman, W.T., Pratt, R.B., Rambal, S., Richter, H., Sack, L., Salleo, S., Schubert, A., Schulte, P., Sparks, J.P., Sperry, J., Teskey, R. and Tyree, M. (2004) The Cohesion Tension Theory. New Phytologist, 163, 447-449.

[30] Nardini, A. and Salleo, S. (2000) Limitation of Stomatal Conductance by Hydraulic Traits: Sensing or Preventing Xylem Cavitation? Trees, 15, 14-24. http://dx.doi.org/10.1007/s004680000071

[31] Tyree, M.T. (2003) Hydraulic Limits on Tree Performance: Transpiration, Carbon Gain and Growth of Trees. Trees, 7, 95-100.

[32] Maherali, H., Moura, C.F., Wilson, C.J. and Jackson, R.B. (2006) Functional Coordination between Leaf Gas Exchange and Vulnerability to Xylem Cavitation in Temperate Forest Trees. Plant Cell, 29, 571-583. http://dx.doi.org/10.1111/j.1365-3040.2005.01433.x

[33] Franks, P.J. (2006) Higher Rates of Leaf Gas Exchange Are Associated with Higher Leaf Hydrodynamic Pressure Gradients. Plant Cell and Environment, 29, 584-592. http://dx.doi.org/10.1111/j.1365-3040.2005.01434.x

[34] Ehret, D.L., Lau, A., Bittman, S., Lin, W. and Shelford, T. (2001) Automated Monitoring of Greenhouse Crops. Agro- 
nomie, 21, 403-414. http://dx.doi.org/10.1051/agro:2001133

[35] Qiu, G.Y., Okushima, L., Sase, S. and In-Bok, L. (2002) Acoustic Emissions in Tomato Plants under Water Stress Conditions. Japan Agricultural Research Quarterly: JARQ, 36, 103-109. http://dx.doi.org/10.6090/jarq.36.103

[36] Yang, S., Lu, P., Okushima, L. and Sase, S. (2007) Precision Irrigation System Based on Detection of Crop Water Stress with Acoustic Emission Technique. Proceedings of the International Conference on Information Acquisition, Jeju City, 8-11 July 2007, 444-447.

[37] Tyree, M.T., Fiscus, E.L., Wullschleger, S.D. and Dixon, M.A. (1986) Detection of Xylem Cavitation in Corn under Field Conditions. Plant Physiology, 82, 597-599. http://dx.doi.org/10.1104/pp.82.2.597

[38] Jia, X.-L., Zhang, L.-H., Ma, R.-K., Wang, Z.-L., Zhang, Q.-G. and Yao, Y.-R. (2006) Ultrasonic Acoustic Emissions from Leaf Xylem of Potted Wheat Subject to a Soil Drought and Rewatering Cycle. Agricultural Sciences in China, 5, 346-355. http://dx.doi.org/10.1016/S1671-2927(06)60060-6

[39] Salleo, S., Nardini, A., Pitt, F. and Lo Gullo, M.A. (2000) Xylem Cavitation and Hydraulic Control of Stomatal Conductance in Laurel (Laurus nobilis L.). Plant, Cell and Environment, 23, 71-79. http://dx.doi.org/10.1046/j.1365-3040.2000.00516.x

[40] Gitz III, D.C., Xin, Z., Baker, J.T., Lascano, R.J. and Burke, J.J. (2012) The Effect of Solar Loading on Soil Temperatures and Developmental Variation in Greenhouse Studies. Agronomy Journal, 104, 388-392. http://dx.doi.org/10.2134/agronj2011.0302N

[41] Lichtenthaler, H.K. (1996) Vegetation Stress: An Introduction to the Stress Concept in Plants. Journal of Plant Physiology, 148, 4-14. http://dx.doi.org/10.1016/S0176-1617(96)80287-2

[42] Brodribb, T.J., McAdam, S.A.M., Jordan, G.J. and Field, T.S. (2009) Evolution of Stomatal Responsiveness to $\mathrm{CO}_{2}$ and Optimization of Water-Use Efficiency among Land Plants. New Phytologist, 183, 839-847. http://dx.doi.org/10.1111/j.1469-8137.2009.02844.x

[43] Maseda, P.M. and Fernández, R.J. (2006) Stay Wet or Else: Three Ways in Which Plants Can Adjust Hydraulically to Their Environment. Journal of Experimental Botany, 57, 3963-3977. http://dx.doi.org/10.1093/jxb/erl127

[44] Woodward, F.I. (1998) Do Plants Really Need Stomata? Journal of Experimental Botany, 49, 471-480. http://dx.doi.org/10.1093/jxb/49.Special Issue.471

[45] Brodribb, T.J. and Holbrook, N.M. (2004) Stomatal Protection against Hydraulic Failure: A Comparison of Coexisting Ferns and Angiosperms. New Phytologist, 162, 663-670. http://dx.doi.org/10.1111/j.1469-8137.2004.01060.x

[46] Cochard, H. (2002) Xylem Embolism and Drought-Induced Stomatal Closure in Maize. Planta, 215, 466-471.

[47] Streck, N.A. (2003) Stomatal Response to Water Vapor Pressure Deficit: An Unsolved Issue. Current Agricultural Science and Technology, 9, 317-322. http://www.periodicos.ufpel.edu.br/ojs2/index.php/CAST/article/view/649/649

[48] Buckley, T.N. (2005) The Control of Stomata by Water Balance. New Phytologist, 168, 275-292. http://dx.doi.org/10.1111/j.1469-8137.2005.01543.x 